\title{
Prognostic stratification of acute pulmonary embolism: Focus on clinical aspects, imaging, and biomarkers
}

REVIEW

Luca Masotti'

Marc Righini ${ }^{2}$

Nicolas Vuilleumier ${ }^{3}$

Fabio Antonelli ${ }^{4}$

Giancarlo Landini ${ }^{5}$

Roberto Cappelli ${ }^{6}$

Patrick Ray ${ }^{7}$

'Internal Medicine, ${ }^{4}$ Clinical Chemistry, Cecina Hospital, Cecina, Italy; ${ }^{2}$ Division of Angiology and Haemostasis, Department of Internal Medicine, Geneva University Hospital, Switzerland; ${ }^{3}$ Division of Laboratory Medicine, Department of Genetics and Laboratory Medicine, Geneva University Hospitals and University of Geneva, Switzerland; ${ }^{5}$ Internal Medicine, Santa Maria Nuova Hospital, Florence, Italy; ${ }^{6}$ Thrombosis Center, University of Siena, Siena, Italy; ${ }^{7}$ Department of Emergency Medicine, Centre Hospitalo-Universitaire Pitié-Salpêtrière, UPMC Paris 6, Paris, France
Correspondence: Luca Masotti UO Medicina Interna, Ospedale di Cecina, Via Montanara, Località Ladronaia, 57023, Cecina (Li), Italy

$\mathrm{Tel}+390586614212$

$\mathrm{Fax}+390586614218$

Email luca.masotti@tin.it

\author{
This article was published in the following Dove Press journal: \\ Vascular Health and Risk Management \\ I July 2009 \\ Number of times this article has been viewed
}

\begin{abstract}
Pulmonary embolism (PE) represents a common disease in emergency medicine and guidelines for diagnosis and treatment have had wide diffusion. However, PE morbidity and mortality remain high, especially when associated to hemodynamic instability or right ventricular dysfunction. Prognostic stratification to identify high risk patients needing to receive more aggressive pharmacological and closer monitoring is of utmost importance. Modern guidelines for management of acute PE are based on risk stratification using either clinical, radiological, or laboratory findings. This article reviews the modern treatment of acute PE, which is customized upon patient prognosis. Accordingly the current risk stratification tools described in the literature such as clinical scores, echocardiography, helical computer tomography, and biomarkers will be reviewed.
\end{abstract}

Keywords: pulmonary embolism, prognosis, troponin, BNP, NT-proBNP, echocardiography, computer tomography

\section{Introduction}

Pulmonary embolism (PE) remains one of the leading causes of morbidity and mortality in the emergency and cardiovascular setting, especially when associated to hemodynamic instability. In the United States, about 150.000 patients per year are diagnosed with acute PE, resulting in thousands of recognized deaths annually from massive PE. Mortality for PE is $2 \%$ in normotensive patients without evidence of right ventricular dysfunction (RVD), but rises up to $30 \%$ in patients with shock and up to $65 \%$ in patients with cardiac arrest at presentation. ${ }^{1}$

Guidelines on diagnosis have had wide diffusion in the last years with strategies based on pre-test clinical probability, D-Dimers levels, ultrasonography of the legs, lung scan, and more recently computer tomography pulmonary angiography (CTPA).$^{2-9}$ Concomitantly modern concepts about mortality risk evaluation, prognostic stratification and consequent treatment have also emerged. Therefore the aim of the present literature review is to summarize the concept of PE risk stratification focusing on emerging stratification tools and discuss its consequences in clinical practice.

\section{Pathophysiology, clinical classification, and modern concepts of treatment of acute PE}

The pathophysiological response to acute PE is of utmost importance to understand its hemodynamic consequences, which in turn will affect patient prognosis. Patient prognosis depends on the extent to which pulmonary artery blood flow is obstructed, 
pre-existing cardiopulmonary disease, and the release of vasoactive humoral factors from clots., ${ }^{1,6}$ The mechanical obstruction formed by the clot, together with the pulmonary artery vasoconstriction stimulated by neurohumoral substances (such as serotonin from platelets, thrombin from plasma, and histamine from tissue) and hypoxemia, could cause increased pulmonary vascular resistance and right side cardiac afterload, which in turn can result in cardiac dilatation, hypokinesis, and myocardial ischemia. In some patients, a rapid progression in systemic arterial hypotension and cardiogenic shock may occur. Cardiac arrest and death could be the fatal evolution. ${ }^{1,6,10}$ This cascade could explain some important consequences in biomarkers increase; myocardial damage represented by micro-infarcts leads to increased levels of cardiac troponins (cTn) and heart type fatty acid-binding proteins (H-FABP), whereas wall stress caused by higher right heart after-load leads to increased levels of natriuretic peptides (NP). Figure 1 summarizes the hemodynamic consequences of PE.

Classically PE has been subdivided in massive, hemodynamically unstable (hypotension is defined as arterial blood pressure less than $90 \mathrm{mmHg}$, shock, or cardiac arrest), submassive (normotensive PE with evidence of RVD) or nonmassive (normotensive PE without RVD), which are both hemodynamically stable. ${ }^{2-5}$ About $5 \%$ of acute PE are represented by massive PE. About $50 \%$ of normotensive patients have trans-thoracic echocardiographic (TTE) pattern of RVD, and around $10 \%$ will die. ${ }^{11}$

The European Society of Cardiology (ESC) recommends classifying PE according to classes of risk for adverse prognosis. ${ }^{12}$ Therefore PE is divided into high risk (corresponding to massive PE with short term mortality $>15 \%$ ) and nonhigh risk. Nonhigh risk patients are normotensive. The presence of increased NP and/ or troponins is currently not mandatory for defining the high risk class. As many normotensive patients often present with RVD and potential adverse outcomes, nonhigh risk $P E$ has been further divided into intermediate risk (corresponding to submassive PE: normotensive plus signs of RVD and/or signs of myocardial damage, short-term mortality being 3\%-15\%) and in low risk (corresponding to nonmassive PE: normotensive without signs of RVD and myocardial damage, short-term mortality $<3 \%$ ). ${ }^{12}$ Figure 2 shows ESC criteria for risk assessment.

Acute treatment of PE is customized by mortality risk based upon prognostic stratification. In their new guidelines, the ESC and American College of Chest Physicians (ACCP) suggest treatment of $\mathrm{PE}$ according to clinical risk. ${ }^{12,13}$ In massive-high risk PE, thrombolysis with alteplase (rtPA), streptokinase, or urokinase is the recommended therapy. Embolectomy could represent an alternative therapy for patients with shock in the acute setting when thrombolysis is contraindicated or when it has been unsuccessful. In submassive-intermediate risk PE, thrombolysis has been proposed in selected patients at high risk for adverse

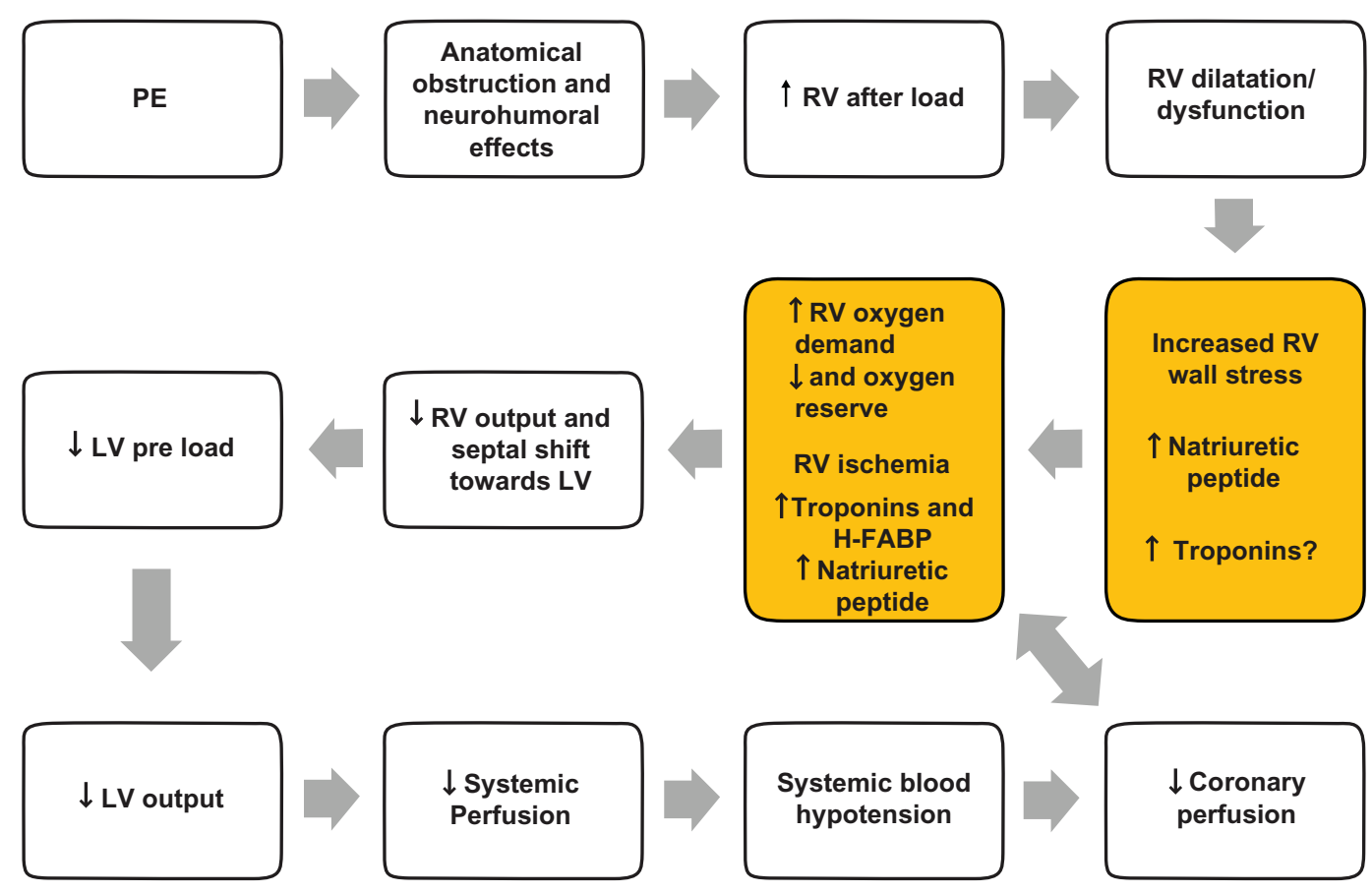

Figure I Pathophysiology of hemodynamic instability due to PE and mechanism of biomarkers increase.

Abbreviations: H-FABP, heart type fatty acid-binding proteins; LV, left ventricular; PE, pulmonary embolism; RV, right ventricular. 


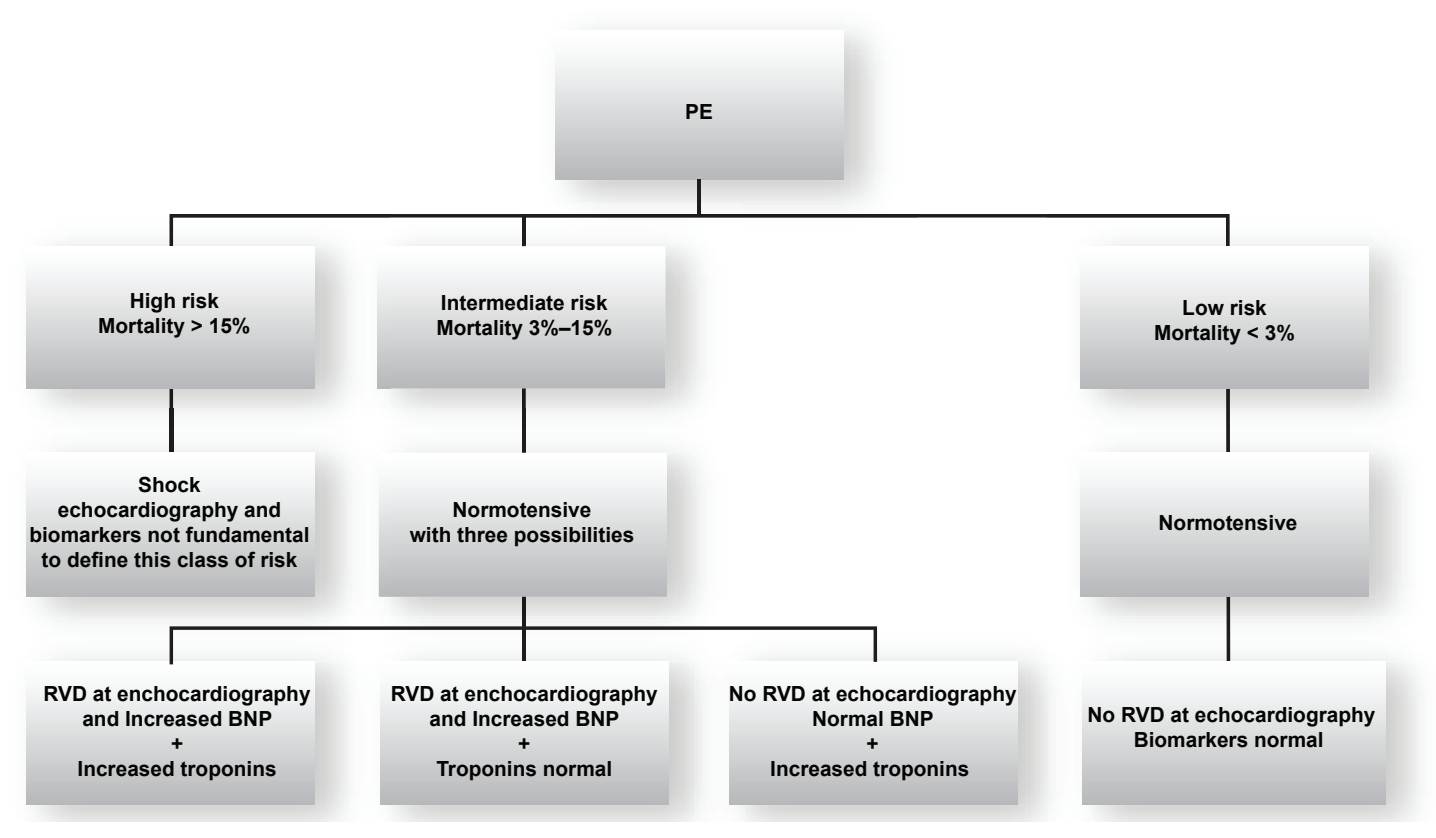

Figure 2 ESC criteria for identifing the risk of adverse prognosis in acute PE.

Abbreviations: BNP, brain natriuretic peptide; ESC, European Society of Cardiology; PF, pulmonary embolism; RVD, right ventricular dysfunction.

prognosis without contraindications (grade IIB of ESC and ACCP VIII Edition) ${ }^{13}$ whereas intravenous unfractioned heparin (UFH) should be reserved to conditions in which thrombolysis is contraindicated (grade IA ESC and ACCP VIII Edition). In nonmassive-low risk PE, subcutaneous low-molecular weight heparins (LMWH) or fondaparinux are recommended (grade IA ESC and ACCP VIII Edition). As this subgroup of patients represent the majority of PE patients and that ambulatory treatment has been reported to be safe, early identification of such patients at admission could potentially lead to a substantial decrease in hospitalization rates and PE-related costs. ${ }^{14,15}$ Vitamin $\mathrm{K}$ antagonists (VKA) should be started in the first day and should be overlapped with UFH and LMWH or fondaparinux for at least five days (grade I A ESC and ACCP VIII Edition). ${ }^{12,13}$

Figure 3 summarizes the choice treatment in different class of risk for patients with acute PE. Thus, PE risk stratification will become fundamental not only to select appropriate treatment strategy, but also to potentially reduce the costs of PE management. For both purposes, several risk stratification algorithms have been reported in the literature, including clinical, radiological, and laboratory parameters.

\section{Risk evaluation and prognostic stratification}

\section{Clinical parameters and clinical scores}

Shock or systemic blood hypotension at presentation represent the most important clinical sign of poor prognosis in patients with acute PE. ${ }^{1,11}$ In the ICOPER Study, the mortality rate was $58.3 \%$ in patients who were hemodynamically unstable at the time of presentation and $15.1 \%$ for those who were hemodynamically stable. ${ }^{11}$ Other clinical variables, easily available at admission, associated to poor prognosis are represented by age over 70 years, history of bed rest over five days, cancer, chronic obstructive pulmonary disease, renal failure, heart failure, cardiovascular diseases, and tachycardia. ${ }^{10}$

The Pulmonary Embolism Prognostic Index (PESI), and Geneva Prediction Rule represent two clinical scores identifying classes of patients with increased risk of adverse outcomes. ${ }^{16,17}$ These scores reliably identify low-risk patients with PE (patients classified as PESI classes I and II) who could be candidates for less costly ambulatory treatment. The major strength of these score is their easy use in all clinical setting; the disadvantage is that they have not been compared to more recent prognostic factors (such as biomarkers and imaging findings). In fact, PESI seems to be more accurate for predicting low risk patients than the Geneva Prediction Rule. ${ }^{18}$ The PESI score tool is displayed in Figure 4.

The shock index, heart rate (beats for minute)/systolic blood pressure $(\mathrm{mmHg})$ ratio, is a simple method to predict high risk patients for adverse outcome, when its value is over 1. This ratio has been shown to be related to in-hospital mortality and it is sensitive to predict poor prognosis alone or in combination with trans-thoracic echocardiogram (TTE). ${ }^{19,20}$ 12-lead ECG findings of poor prognosis are represented by 


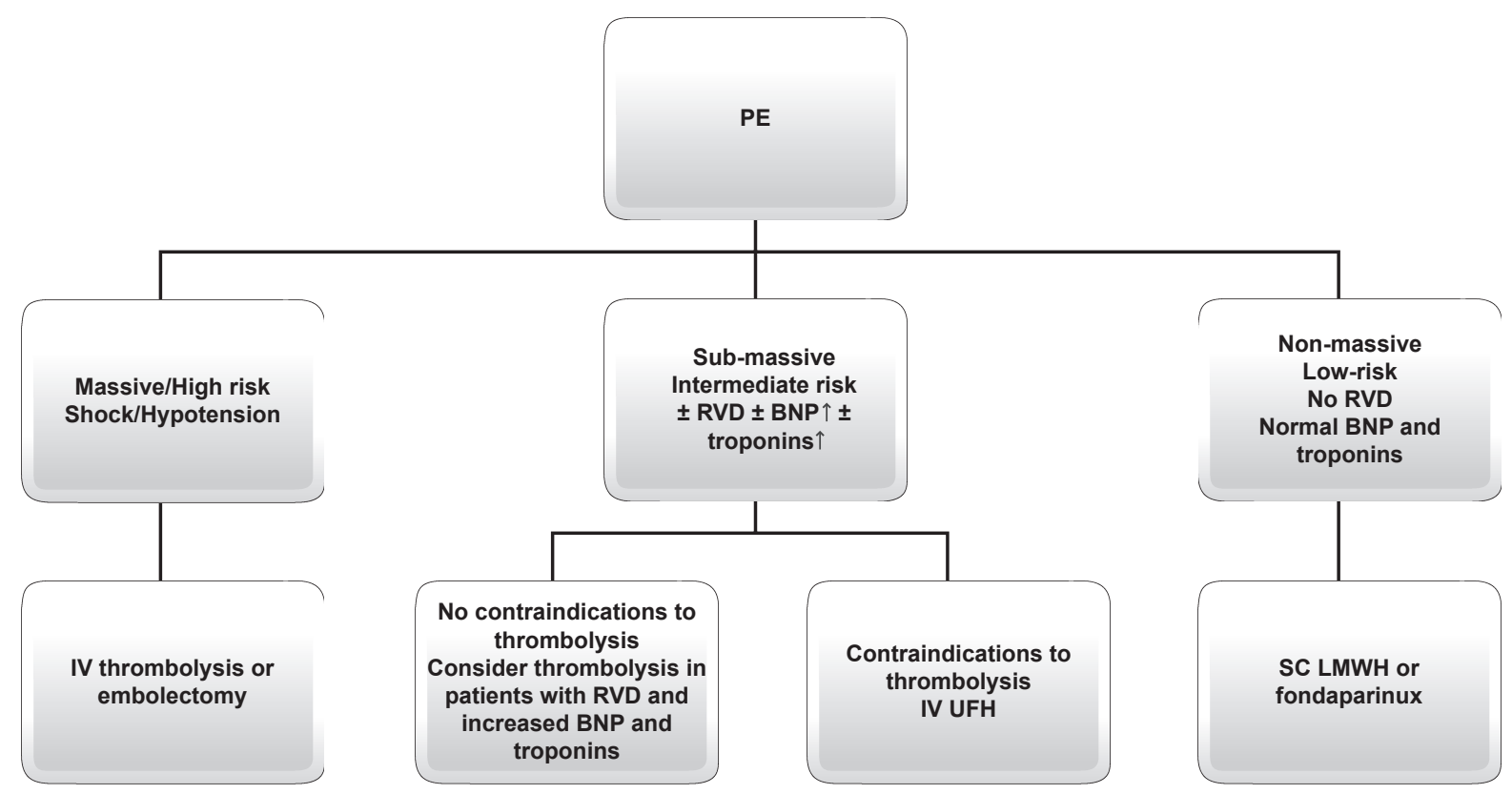

Figure 3 PE treatment according to modern guidelines.

Abbreviations: BNP, brain natriuretic peptide; RHD, right heart dysfunction; IV, intravenous; SC, subcutaneous.

presence and number of $\mathrm{T}$ waves inversion in precordial leads and QR in V1, ${ }^{21-23}$ but overall, ECG does not seem to be a reliable marker of severity of $\mathrm{PE}$.

\section{Echocardiographic and radiological parameters}

TTE represents the most useful tool in everyday clinical practice to show RVD because of its noninvasive nature and relative low cost. Hence, RVD assessed on TTE has been described as one of the strongest predictor of early mortality in nonmassive PE. ${ }^{24-26}$

The main TTE findings detectable in PE are represented by right ventricle hypokinesis (mild, moderate, severe), right ventricle dilatation (especially represented by four chambers end-diastolic RV/left ventricular [LV] ratio $>1$ ), and signs of pulmonary hypertension. The presence of RVD is related to poor prognosis in PE with hemodynamic instability. ${ }^{11,25}$ Furthermore, TTE detects RVD in about $30 \%-40 \%$ of

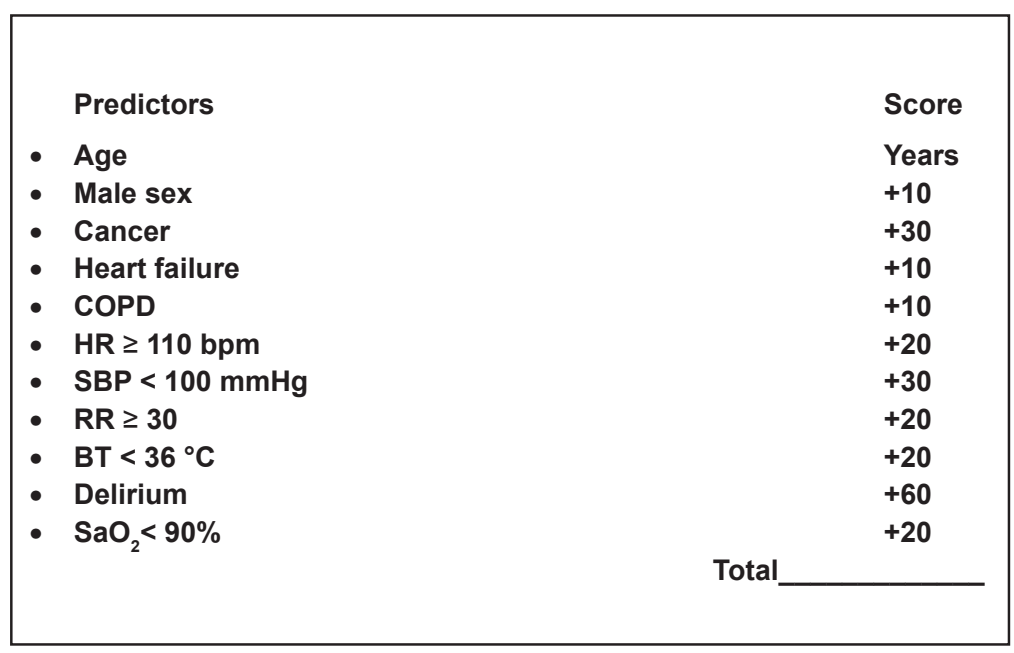

Low risk

$\leq 65$ class I, mortality $0.7 \%$

$66-85$ class II, mortality $1.2 \%$

High risk

$86-105$ class III, mortality $4.8 \%$

$106-125$ class IV, mortality $13.6 \%$

$>125$ class $V$, mortality $25 \%$

Figure 4 Pulmonary embolism severity index (P.E.S.I). Modified from Aujesky D, Perrier A, Roy PM, et al.Validation of a clinical prognostic model to identify low-risk patients with pulmonary embolism.J Intern Med. 2007;261:597-604.

Abbreviations: COPD, chronic obstructive pulmonary disease; HR, heart rate; bpm, beats per minute; SBP, systolic blood pressure; RR, respiratory rate; BT, body temperature; $\mathrm{SaO}_{2}$, arterial saturation of oxygen. 
normotensive patients (systolic blood pressure $>90 \mathrm{mmHg}$ ) at presentation. ${ }^{24,25}$ Thirty-day mortality of normotensive patients with RVD is two-fold compared to normotensive patients without RVD. ${ }^{27}$ RVD at presentation seems also to predict poor pulmonary clot resolution six months after the initial event and a higher incidence of VTE recurrence. ${ }^{28}$ Fremont and colleagues reported data from a monocentric study enrolling more than 1400 patients. The authors found that an TTE RV/LV diameter ratio $>0.9$ was an independent risk factor for hospital mortality in normotensive patients with PE. ${ }^{29}$ A recent review has shown that in-hospital mortality of normotensive patients without RVD was $0 \%-9.6 \%$ compared to $11.8 \%-23 \%$ for patients with RVD. ${ }^{30}$ However other studies which evaluated the prognostic value of TTE in normotensive PE patients were less convincing. ${ }^{31,32}$ The limit of TTE examination is that the test is operator-dependent and not necessarily available around the clock in all institutions. Moreover TTE criteria of RVD are not definitely established.

Currently, CTPA represents the diagnostic gold standard for $\mathrm{PE}$, and is widely integrated in validated diagnostic strategies. ${ }^{6-8,33}$ Recently several studies focused on the correlation between findings of CTPA, presence of RVD, and prognosis of PE. ${ }^{34-42}$ The Computer Tomography Pulmonary Embolism (CTPE) index combines distribution and severity of vascular obstruction of clots in pulmonary circulation; PE severity seems to be linearly related to CTPE index values. ${ }^{40}$ Ghanima and colleagues have proposed to divide the pulmonary vascular tree in four groups of arteries: sub-segmental, segmental, lobar, and main pulmonary artery with its (left and right) branches (respectively named 1, 2, 3, 4). ${ }^{41}$ These authors showed that the pulmonary artery obstruction index was correlated to troponin T levels, CTPA RV/LV diameter ratio and partial pressure of oxygen in arterial blood $\left(\mathrm{PaO}_{2}\right){ }^{41}$ It seems that the Ghanima index could be related also to TTE RVD. ${ }^{43} \mathrm{~A}$ RV/LV diameter ratio is also easily determined by CTPA and the thirty-day mortality rate is $15.6 \%$ in patients with CTPA RV/LV > 0.9 compared to $7.7 \%$ in patients without RV enlargement. ${ }^{42}$ However these results have not been confirmed in the PIOPED II trial. ${ }^{44}$ Finally, CTPA seems to be a promising method for PE prognosis stratification, but the sample size of these previous studies precludes any firm conclusion. Thus, further studies are warranted to assess CTPA as a prognostic tool, because it could be very useful for clinicians to have at the same time a validated diagnostic tool, with an additional prognostic value.

Pulmonary real-time magnetic resonance (rtMR) and magnetic resonance angiography (MRA) represent a safe alternative and/or complementary examination compared with CTPA both as diagnostic imaging and for detecting RV enlargement or dysfunction. ${ }^{45-49}$

\section{Laboratory parameters}

Arterial blood gas analysis (BGA) remains a first-line examination in patients with suspected $\mathrm{PE}$ for evaluation of gas exchange and acid-base status. The role of BGA as prognosticator has been studied with discordant results between younger and elderly patients. Much recently hypoxemia was found as an independent negative predictor of three-month all-cause mortality in PE patients (hazard ratio [HR] 5.7, 95\% confidence interval [CI]: 2.1-15.1). ${ }^{50} \mathrm{PaO}_{2}$ values have been demonstrated to be linearly associated to CTPA parameters such as proximal extension of pulmonary clots and RV/LV diameter. ${ }^{41}$ Parameters derived from BGA, such as alveolar-arterial oxygen gradient (values $>50 \mathrm{mmHg}$ ) and arterial-alveolar oxygen tension ratio (values $<0.50$ ) have been demonstrated to be associated to poor prognosis in nonelderly patients with PE. ${ }^{51,52}$ Moreover, alveolar dead space measured from volumetric capnography and BGA seems to correlate with embolic burden of PE. ${ }^{53}$ In elderly PE patients, only lower arterial oxygen saturation seems to predict short-term mortality; neither $\mathrm{PaO}_{2}$ nor alveolar-arterial oxygen gradient seem to identify high risk patients. ${ }^{54}$

D-Dimer values seems to be linearly related to the extend of the clot and the severity of PE..$^{43,55-57}$ One study demonstrated that patients who had D-Dimer levels below $1500 \mu \mathrm{g} / \mathrm{L}$ have a very low mortality. ${ }^{56}$

As detailed below, cardiac biomarkers, such as cardiac troponins, (cTnI and cTnT), NP, H-FABP, myoglobin, and growth differentiation factor- 15 have been extensively evaluated as risk stratification tools in PE.

Troponins are released in the bloodstream in presence of myocardial damage secondary to microinfarction. ${ }^{58}$ The increase of troponins is correlated with TTE RVD and CTPA findings and its elevation has a strong negative prognostic value. ${ }^{59}$ Many studies have demonstrated the negative prognostic values of increased troponins in PE. ${ }^{60-64}$ Becattini and colleagues have published a meta-analysis on the relation between troponins and mortality and morbidity in acute PE. ${ }^{65}$ They confirmed that the increase of troponins I and/or T was associated with a higher mortality (17.9\% in patients with elevated troponin levels and $2.3 \%$ in patients with normal troponin levels), even in the subgroup of hemodynamically stable patients (odds ratio, 4.12). ${ }^{65,66}$ Jimenez and colleagues also confirmed in a large prospective study that elevated cTnI predicted fatal PE in hemodynamically stable patients; the negative predictive value of a negative cTnI for mortality was $93 \%{ }^{67}$ 
NP secretion is due to RV wall strech and therefore due to RVD. ${ }^{68}$ The increase of the B (B type) NP biomarker (BNP and its amino terminal portion, NT-proBNP) is highly sensitive but poorly specific for detecting RVD and patients at risk of severe adverse events such as cardiac arrest, shock, need for thrombolysis or vasopressors or mechanical ventilation, or need for intensive care units. ${ }^{69-83}$ Two studies suggested that NT-proBNP correlated better with prognosis when compared to troponins, ${ }^{84,85}$ especially in combination with TTE. ${ }^{84}$ Several recent reviews and meta-analyses strongly confirmed the prognostic usefulness of NP. ${ }^{86-89}$

H-FABP, a small cytosolic protein released earlier than troponins into circulation when the myocardium is injured, has been evaluated as a prognostic tool and small studies suggested that this cardiac biomarker could also identify the patients with poorer outcomes when compared to cTns and BNP/NT-proBNP. ${ }^{90,91}$ The negative prognostic role of myoglobin and growth-differentiation factor-15 (gdf-15), a cytokine induced in the heart after ischemia or pressure overload, in acute PE have also been reported. ${ }^{92,93}$ However, H-FABP and gdf-15 measurements are not yet widely available.

Figure 5 summarizes the results of studies which evaluated various clinical, instrumental, and laboratory indexes for predicting poor outcomes in acute PE. This figure suggests that cardiac biomarkers have all been shown to correlate with $\mathrm{RV}$ dysfunction/dilatation and prognosis in PE.

However, because most of those studies did not perform an extensive comparison between all the available biomarkers, knowing which one will yield the best prognostic value still remains debated. Among other limitations worth to be mentioned are that different biomarkers thresholds were used (and often determined retrospectively), and that various outcome definitions were used in the aforementioned studies. In order to compare their respective prognostic value, it will be necessary to use uniform pre-defined cut-offs. One possibility would be to use the cut-offs validated in their respective initial context. To this respect, a small systematic prospective comparative study using the pre-defined and validated thresholds (either in acute coronary syndrome or heart failure) for NTproBNP, BNP, H-FABP, and myoglobin showed that only NPs (BNP or NT-proBNP) were significantly correlated with RV dilatation on CTPA. ${ }^{94}$ Those results are corroborated by a recent multicentre study showing that NT-proBNP appeared as the most effective biomarker for rule-out purposes in nonmassive PE. ${ }^{95}$ Using the commonly defined cut-off of 300 $\mathrm{pg} / \mathrm{ml}$ validated for heart failure, ${ }^{96}$ this test had a negative predictive value of $100 \%$ (95\% CI: 91-100). ${ }^{95}$

Defining which of those biomarkers should be used as rule-out or rule-in test needs further clarification, but based

- Clinical parameters

- Shock/Hypotension

- Shock index

- PESI

- Instrumental parameters

- 12-lead ECG

- Echocardiography

- CTPA

- Laboratory parameters

\author{
$\mathrm{SBP} \leq 90 \mathrm{mmHg}$ \\ $>1$ \\ Class III, IV, V
}

\author{
Presence and number of $\mathrm{T}$ waves \\ Inversion in precordial leads \\ RVD findings \\ CPTE index, proximal clot \\ $\mathrm{RV} / \mathrm{RV}$ diameter ratio $>1$
}

- Increasing

troponins I or T, BNP or NT-proBNP,

H-FABP, myoglobin, GDF-15

Figure 5 Clinical, instrumental and laboratory parameters associated with adverse outcomes in patients with acute PE.

Abbreviations: SBP, systolic blood pressure; ECG, echocardiogram; ESI, Pulmonary Embolism Severity Index; RVD, right ventricular dysfunction; CTPA, computer tomography pulmonary angiography; BNP, brain natriuretic peptides; HTFABP, heart type fatty acid binding protein; GFD-I5, Growth differentiation factor- I5; CTPE, computer tomography pulmonary embolism. 
upon the aforementioned observations, it appears that BNP/ NT-proBNP and cTnI could potentially be used as rule-out tests. Finally, determining whether a biomarker alone or in combination with other clinical or radiological or ECG features would add incremental prognostic value deserves further study. Overall, NP (BNP or NT-proBNP) and cTns, with their 24-hour availability in most of emergency laboratories, could represent very convenient prognostic tools for $\mathrm{PE}$ risk stratification in an acute setting, especially in the institutions where echocardiography is not widely available.

Concerning the identification of patients, two major points are under investigation. First, it becomes of utmost importance to select patients who may be safely treated on an outpatient basis, and both clinical scores ${ }^{97}$ or probably biomarkers like NT-pro-BNP ${ }^{95}$ may fulfil this request. This hypothesis is being currently tested in a prospective study (the OTPE trial). ${ }^{98}$ Second, there is a need to better define which patient may benefit from fibrinolysis, and at least one randomized study is comparing anticoagulation against fibrinolysis in patients with no hemodynamic failure and RVD on TTE. ${ }^{99}$ These currently ongoing studies should allow improvements in the care of PE patients in the near future.

\section{Conclusions}

Risk evaluation and prognostic stratification are the cornerstones of modern acute PE management. The use of either clinical, ECG, or biochemical parameters will probably be crucial to appropriately select stable patients for fibrinolyis, which currently represents one of the utmost therapeutic challenges of PE. For the time being, the remaining questions are: 1) which treatment should be reserved to submassive PE patients? 2) What is the best modality to identify such patients: TTE, CTPA, biomarkers, or clinical scores? 3) Could a combination of such stratification tools add incremental value to one modality alone?

Intend-to-treat and noninferiority trials are now requested to resolve those matters. In this respect, the results of ongoing randomized multicenter trials, such as the European Pulmonary Embolism Thrombolysis (PEITHO) trial, ${ }^{99}$ are eagerly awaited.

\section{Disclosure}

The authors report no conflicts of interest in this work.

\section{References}

1. White RH. The epidemiology of venous thromboembolism. Circulation. 2003;107(Suppl 1):I4-8.

2. British Thoracic Society Standards of Care Committee Pulmonary Embolism Guideline Development Group. British Thoracic Society guidelines for the management of suspected acute pulmonary embolism. Thorax. 2003;58:470-484.
3. ESC Task Force. Guidelines on diagnosis and management of acute pulmonary embolism. Eur Heart J. 2000;21:1301-1336.

4. Tapson VF, Carroll BA, Davidson BL, et al. The diagnostic approach to acute venous thromboembolism. Clinical practice guideline. American Thoracic Society. Am J Respir Crit Care Med. 1999;160: 1043-1066.

5. American College of Emergency Physicians Clinical Policies Committee; Clinical Policies Committee Subcommittee on Suspected Pulmonary Embolism. Clinical policy: critical issues in the evaluation and management of adult patients presenting with suspected pulmonary embolism. Ann Emerg Med. 2003;41:257-270.

6. Goldhaber SZ, Elliott CG. Acute pulmonary embolism: part I. Epidemiology, pathophysiology, and diagnosis. Circulation. 2003;108:2726-2729.

7. Stein PD, Woodard PK, Weg JG, et al. Diagnostic pathways in acute pulmonary embolism: recommendations of the PIOPED II investigators. Am J Med. 2006;119:1048-1055.

8. Writing Group for Christopher Study Investigators. Effectiveness of managing suspected pulmonary embolism using an algorithm combining clinical probability, D-dimer testing, and computer tomography. JAMA. 2006;295:172-179.

9. Le Gal G, Righini M, Roy PM, et al. Prediction of pulmonary embolism in the emergency department: the revised Geneva score. Ann Intern Med. 2006;144:165-171.

10. Becattini C, Agnelli G. Acute pulmonary embolism: risk stratification in the emergency department Intern Emerg Med. 2007;2:119-129.

11. Goldhaber SZ, Visani L, De Rosa M. Acute pulmonary embolism: clinical outcomes in the International Cooperative Pulmonary Embolism Registry (ICOPER). Lancet. 1999;353:1386-1389.

12. Torbicki A, Perrier A, Konstantinides S, et al. Guidelines on the diagnosis and management of acute pulmonary embolism of the European Society of Cardiology. Eur Heart J. 2008;29:2276-2315.

13. Kearon C, Kahn SR, Agnelli G, Goldhaber SZ, Raskob GE, Comerota AJ. Antithrombotic therapy in neonates and children: American College of Chest Physicians Evidence-Based Clinical Practice Guidelines (8th Edition). Chest. 2008;133:454S-545S.

14. Kovacs MJ, Anderson D, Morrow B, et al. Outpatient treatment of pulmonary embolism with dalteparin. Thromb Haemost. 2000;83: 209-211.

15. Beer JH, Burger M, Gretener S, Bernard Bagattini S, Bounameaux H. Outpatients treatment of pulmonary embolism is feasible and safe in a substantial proportion of patients. J Thromb Haemost. 2003;1:186-187.

16. Aujesky D, Perrier A, Roy PM, et al. Validation of a clinical prognostic model to identify low-risk patients with pulmonary embolism. J Intern Med. 2007;261:597-604.

17. Wicki J, Perrier A, Perneger TV, et al. Predicting adverse outcome in patients with acute pulmonary embolism: a risk score. Thromb Haemost. 2000;84:548-552.

18. Jimenez D, Yusen RG, Otero R, et al. Prognostic models for selecting patients with acute pulmonary embolism for initial outpatient therapy. Chest. 2007;132:24-30.

19. Toosi MS, Merlino JD, Leeper KV. Prognostic value oft he shock index along with thransthoracic echocardiography in risk stratification of patients with pulmonary embolism. Am J Cardiol. 2008;101:700-705.

20. Otero R, Trujillo-Santos J, Cayuela A, et al. Registro Informatizado de la Enfermedad Tromboembolica (RIETE) Investigators. Haemodynamically unstable pulmonary embolism in the RIETE Registry: systolic blood pressure or shock index? Eur Respir J. 2007;30:1111-1116.

21. Jimenez D. ECG for risk stratification in patients with pulmonary embolism. Eur Respir J. 2005;26:366-367.

22. Toosi MS, Merlino JD, Leeper KV. Electrocardiographic score and short term outcomes of acute pulmonary embolism. Am J Cardiol. 2007;100:1172-1176.

23. Kucher N, Walpoth N, Wustmann K, Noveanu M, Gertsch M. QR in V1an ECG sign associated with right ventricular strain and adverse clinical outcome in pulmonary embolism. Eur Heart J. 2003;24:1113-1119. 
24. Goldhaber SZ. Echocardiography in the management of pulmonary embolism. Ann Intern Med. 2002;136:691-700.

25. Kreit JW. The impact of right ventricular dysfunction on the prognosis and therapy of normotensive patients with pulmonary embolism. Chest. 2004;125:1539-1545.

26. Vieillard-Baron A, Page B, Augarde R, et al. Acute cor pulmonale in massive pulmonary embolism: incidence, echocardiographic pattern, clinical implications and recovery rate. Intensive Care Med. 2001;27:1481-1486.

27. Kucher N, Rossi E, De Rosa M, Goldhaber SZ. Prognostic role of echocardiography among patients with acute pulmonary embolism and a systolic arterial pressure of $90 \mathrm{mmHg}$ or higher. Arch Intern Med. 2005;165:1777-1781

28. Kaczynska A, Kostrubiec M, Pacho R, Kunikowska J, Pruszczyk P. Elevated D-Dimer concentration identifies patients with incomplete recanalization of pulmonary artery thromboemboli despite 6 months after the first episode of acute pulmonary embolism. Thromb Res. 2008;122:21-25.

29. Frémont B, Pacouret G, Jacobi D, Puglisi R, Charbonnier B, de Labriolle A. Prognostic value of echocardiographic right/left ventricular end-diastolic diameter ratio in patients with acute pulmonary embolism: results from a monocenter registry of 1,416 patients. Chest. 2008;133:358-362.

30. Gibson N, Sohne M, Buller H. Prognostic value of echocardiography and spiral computer tomography in patients with pulmonary embolism. Curr Opin Pulm Med. 2006;11:380-384.

31. Lualdi JC, Goldhaber SZ. Right ventricular dysfunction after acute pulmonary embolism: pathophysiologic factors, detection, and therapeutic implications. Am Heart J. 1995;30:1276-1282.

32. ten Wolde M, Söhne M, Quak E, Mac Gillavry MR, Büller HR. Prognostic value of echocardiographically assessed right ventricular dysfunction in patients with pulmonary embolism Arch Intern Med. 2004;164:1685-1689.

33. Ghaye B, Ghuysen A, Bruyere PJ, D'Orio V, Dondelinger RF. Can CT pulmonary angiography allow assessment of severity and prognosis in patients presenting with pulmonary embolism? What the radiologist needs to know. Radiographics. 2006;26:23-40.

34. Araoz PA, Gotway MB, Harrington JR, Harmsen WS, Mandrekar JN. Pulmonary embolism: prognostic CT findings. Radiology. 2007;242: 889-897.

35. Schoepf UJ, Castello P. CT angiography for diagnosis of pulmonary embolism: state of the art. Radiology. 2004;230:329-337.

36. van der Meer RW, Pattynama PM, van Strijen MJ, et al. Right ventricular dysfunction and pulmonary obstruction index at helical CT: prediction of clinical outcome during 3-month follow-up in patients with acute pulmonary embolism. Radiology. 2005;235:798-803.

37. Ghuysen A, Ghaye B, Willems V, et al. Computed tomographic pulmonary angiography and prognostic significance in patients with acute pulmonary embolism. Thorax. 2005;60:956-961.

38. Mansencal N, Joseph T, Vieillard-Baron A, et al. Diagnosis of right ventricular dysfunction in acute pulmonary embolism using helical computed tomography. Am J Cardiol. 2005;95:1260-1263.

39. Schoepf UJ, Kucher N, Kipfmueller F, Quiroz R, Costello P, Goldhaber SZ. Right ventricular enlargement on chest computed tomography: a predictor of early death in acute pulmonary embolism. Circulation. 2004;110:3276-3280.

40. Qanadli SD, El Hajjam M, Viellard-Baron A, et al. New CT index to quantify arterial obstruction in pulmonary embolism: comparison with angiographic index and echocardiography. AJR Am J Roentgenol. 2001;176:1415-1420.

41. Ghanima W, Abdelnoor M, Holmen LO, Nielssen BE, Sandset PM. The association between the proximal extension of the clot and the severity of pulmonary embolism (PE): a proposal for a new radiological score for PE. J Intern Med. 2007;261:74-81.

42. Wu AS, Pezzullo JA, Cronan JJ, Hou DD, Mayo-Smith WW. CT pulmonary angiography: quantification of pulmonary embolus as a predictor of patient outcome-initial experience. Radiology. 2004;230:831-835.

43. Masotti L, Antonelli F, Venturini E, Landini GC. Cardiac troponin I and plasma D-dimer are related to proximal and bilateral extension of clots and right cardiac dysfunction in patients with pulmonary embolism. J Intern Med. 2007;262:588-589.
44. Stein PD, Beemath A, Matta F, et al. Enlarged right ventricle without shock in acute pulmonary embolism: prognosis. Am J Med. 2008; 121:34-42.

45. Stein PD, Woodard PK, Hull RD, et al. Gdolinium-enhanced magnetic resonance angiography for detection of acute pulmonary embolism. Chest. 2003;124:2324-2328.

46. Haage P, Piroth W, Krombach G, et al. Pulmonary embolism. Comparison of angiography with spiral computer tomography, magnetic resonance angiography, and real-time magnetic resonance imaging. Am J Respir Crit Care Med. 2003;167:729-734.

47. Pleszewski B, Chartrand-Lefebvre C, Qanadli SD, et al. Gadoliniumenhanced pulmonary magnetic resonance angiography in the diagnosis of acute pulmonary embolism: a prospective study on 48 patients. Clin Imaging. 2006;30:166-172.

48. Blum A, Bellou A, Guillemin F, et al. Performance of magnetic resonance angiography in suspected acute pulmonary embolism. Thromb Haemost. 2005;93:503-511.

49. Kluge A, Muller C, Hansel J, Gerriets T, Bachmann G. Real-time MR with TrueFISP for the detection of acute pulmonary embolism: initial clinical experience. Eur Radiol. 2004;14:709-718.

50. Bova C, Pesavento R, Marchiori A, et al. Risk stratification and outcomes in hemodinamically stable patients with acute pulmonary embolism. A prospective, multicentre, cohort study with three months of follow-up. J Thromb Hemost. 2009 Mar 19. [Epub ahead of print].

51. Hsu JT, Chu CM, Chang ST, et al. Prognostic value of arterial/alveolar oxygen tension ratio (a/APO2) in acute pulmonary embolism. Circ J. 2007;71:1560-1566.

52. Hsu JT, Chu CM, Chang ST, et al. Prognostic role of alveolar-arterial oxygen pressure difference in acute pulmonary embolism. Circ $J$. 2006;70:1611-1616.

53. Kline JA, Kubin AK, Patel MM, Easton EJ, Seupal RA. Alveolar dead space as a predictor of severity of pulmonary embolism. Acad Emerg Med. 2000;7:611-617.

54. Masotti LO, Ceccarelli E, Cappelli R, Barabesi L, Forconi S. Arterial blood gas analysis and alveolar-arterial oxygen gradient in diagnosis and prognosis of elderly patients with suspected pulmonary embolism. J Gerontol A Biol Sci Med Sci. 2000;55A:M760-M764.

55. Ghanima W, Abdelnoor M, Holmen LO, Nielsen BE, Ross S, Sandset PM. D-Dimer level is associated with the extent of pulmonary embolism. Thromb Res. 2007;120:281-288.

56. Aujesky D, Roy PM, Guy M, Cornuz J, Sanchez O, Perrier A. Prognostic value of D-Dimer in patients with pulmonary embolism. Thromb Haemost. 2006;96:478-482.

57. De Monyè W, Sanson BJ, Mac Gillavry MR, et al. Embolus location affects the sensitivity of a rapid quantitative D-Dimer assay in the diagnosis of pulmonary embolism. Am J Respir Crit Care Med. 2002;165:345-348.

58. Becattini C, Vedovati MC, Agnelli G. Diagnosis and prognosis of acute pulmonary embolism: focus on troponins. Expert Rev Mol Diagn. 2008;8:339-349.

59. Muller-Bardorff M, Weidtmann B, Giannitsis E, et al. Release kinetics of cardiac troponin $\mathrm{T}$ in survivors of confirmed severe pulmonary embolism. Clin Chem. 2002;48:673-675.

60. Giannitsis E, Muller-Bardorff M, Kurowski V, et al. Independent prognostic value of cardiac troponin $T$ in patients with confirmed pulmonary embolism. Circulation. 2000;102:211-217.

61. Konstantinides S, Geibel A, Olschewski M, et al. Importance of cardiac troponins I and $\mathrm{T}$ in risk stratification of patients with acute pulmonary embolism. Circulation. 2002;106:1263-1268.

62. Pruszczyk P, Bochowicz A, Torbicki A, et al. Cardiac troponin T monitoring identifies high risk group of normotensive patients with acute pulmonary embolism. Chest. 2003;123:1947-1952.

63. Janata K, Holzer M, Laggner AN, Mullner M. Cardiac troponin T in the severity assessment of patients with pulmonary embolism: cohort study. BMJ. 2003;326:312-313.

64. Kucher N, Goldhaber SZ. Cardiac biomarkers for risk stratification of patients with acute pulmonary embolism. Circulation. 2003;108: 2191-2194 
65. Becattini C, Vedovati MC, Agnelli G. Prognostic value of troponins in acute pulmonary embolism: a meta-analysis. Circulation. 2007;116:427-433.

66. Becattini C, Agnelli G. Predictors of mortality from pulmonary embolism and their influence on clinical management. Thromb Haemost. 2008; 100:747-751.

67. Jimènez D, Diaz G, Molina J, et al. Troponin I and risk stratification of patients with acute non massive pulmonary embolism. Eur Respir J. 2008;31:847-853.

68. Ray P, Delerme S, Jourdain P, Chenevier-Gobeaux C. Differential diagnosis of acute dyspnea: the value of $\mathrm{B}$ natriuretic peptides in the emergency department. QJM. 2008;101:831-843.

69. ten Wolde M, Tulevski II, Mulder JW, et al. Brain natriuretic peptide as a predictor of adverse outcome in patients with pulmonary embolism. Circulation. 2003;107:2082-2084.

70. Kucher N, Printzen G, Goldhaber SZ. Prognostic role of brain natriuretic peptide in acute pulmonary embolism. Circulation. 2003;107:2545-2547.

71. Kruger S, Graf J, Merx MW, et al. Brain natriuretic peptide predicts right heart failure in patients with acute pulmonary embolism. Am Heart $J$. 2004;147:60-65.

72. Kiely DG, Kenneby NS, Pirzada O, Batchelor SA, Struthers SA, Lipworth BJ. Elevated levels of natriuretic peptides in patients with pulmonary thromboembolism. Respir Med. 2005;99:1286-1291.

73. Söhne M, Ten Wolde M, Boomsma F, Reitsma JB, Douketis JD, Büller HR. Brain natriuretic peptide in hemodinamically stable acute pulmonary embolism. J Thromb Haemost. 2006;4:552-556.

74. Pieralli F, Olivotto I, Vanni S, et al. Usefulness of bedside testing for brain natriuretic peptide to identify right ventricular dysfunction and outcome in normotensive patients with acute pulmonary embolism. Am J Cardiol. 2006;97:1386-1390.

75. Ray P, Maziere F, Medimagh S, et al. Evaluation of B-type natriuretic peptide to predict complicated pulmonary embolism in patients aged 65 years and older: a brief report. Am J Emerg Med. 2006;26:603-607.

76. Logeart D, Lecuyer L, Thabut G, et al. Biomarker-based strategy for screening right ventricular dysfunction in patients with non-massive pulmonary embolism. Intensive Care Med. 2007;33:286-292.

77. Tulevski II, ten Wolde M, van Veldhuisen DJ, et al. Combined utility of brain natriuretic peptide and cardiac troponin $\mathrm{T}$ may improve rapid triage and risk stratification in normotensive patients with pulmonary embolism. Int J Cardiol. 2007;116:161-166.

78. Vuilleumier N, Righini M, Perrier A, et al. Correlation between cardiac biomarkers and right ventricular enlargement on chest $\mathrm{CT}$ in non massive pulmonary embolism. Thromb Res. 2008;121:617-624.

79. Yardan T, Altintop L, Baydin A, Yilmaz O, Guven H. B-type natriuretic peptide as an indicator of right ventricular dysfunction in acute pulmonary embolism. Int J Clin Pract. 2008;62:1177-1182.

80. Pruszczyk P, Kostrubiec M, Bochowicz A, et al. N-terminal natriuretic peptide in patients with acute pulmonary embolism. Eur Repir J. 2003;22:649-653.

81. Kostrubiec M, Pruszczyk P, Bochowicz A, et al. Biomarker-based strategy risk assessment model in acute pulmonary embolism. Eur Heart J. 2005;26:2166-2172.

82. Kostrubiec M, Pruszczyk P, Kaczynska A, Kucher N. Persistent NT-proBNP elevation in acute pulmonary embolism predicts early death. Clin Chim Acta. 2007;382:124-128.
83. Kline JA, Zeitouni R, Marchick MR, Hernandez-Nino J, Rose GA Comparison of 8 biomarkers for prediction of right ventricular hypokinesis 6 months after submassive pulmonary embolism. Am Heart $J$. 2008;156:308-314.

84. Binder L, Pieske B, Olschewski M, et al. N-terminal pro-brain natriuretic peptide or troponin testing followed by echocardiography for risk stratification of acute pulmonary embolism. Circulation. 2005;112:1573-1579.

85. Maziere F, Birolleau S, Medimagh S, et al. Comparison of troponin I and N-terminal-pro B-type natriuretic peptide for risk stratification in patients with pulmonary embolism. Eur J Emerg Med. 2007;14:207-211.

86. Klok FA, Mos IC, Huisman MV. Brain-type natriuretic peptide levels in the prediction of adverse outcome in patients with pulmonary embolism: a systematic review and meta-analysis. Am J Respir Crit Care Med. 2008; 178:425-430.

87. Coutance G, Le Page O, Lo T, Hamon M. Prognostic value of brain natriuretic peptide in acute pulmonary embolism. Crit Care. 2008;12:R109.

88. Cavallazzi R, Nair A, Vasu T, Marik PE. Natriuretic peptides in acute pulmonary embolism: a systematic review. Intensive Care Med. 2008;34:2147-2156.

89. Sanchez O, Tringuart L, Colombet I, et al. Prognostic value of right ventricular dysfunction in patients with haemodynamically stable pulmonary embolism: a systematic review. Eur Heart J. 2008;29:1569-1577.

90. Puls M, Dellas C, Lankeit M, et al. Heart-type fatty acid-binding protein permits early risk stratification of pulmonary embolism. Eur Heart $J$. 2007;28:224-229.

91. Kaczyñska A, Pelsers MM, Bochowicz A, Kostrubiec M, Glatz JF, Pruszczyk P. Plasma heart-type fatty acid binding protein is superior to troponin and myoglobin for rapid risk stratification in acute pulmonary embolism. Clin Chim Acta. 2006;371:117-123.

92. Pruszczyk P, Bochowicz A, Kostrubiec M, et al. Myoglobin stratifies short-term risk in acute major pulmonary embolism. Clin Chim Acta. 2003;338:53-56.

93. Lankeit M, Kempf T, Dellas C, et al. Growth differentiation factor-15 for prognostic assessment of patients with acute pulmonary embolism. Am J Respir Crit Care Med. 2008;177:1018-1025.

94. Vuilleumier N, Righini M, Perrier A, et al. Correlation between cardiac biomarkers and right ventricular enlargement on chest $\mathrm{CT}$ in non massive pulmonary embolism. Thromb Res. 2008;121:617-624.

95. Vuilleumier N, Le Gal G, Verschuren F, et al. Cardiac biomarkers for risk stratification in non massive pulmonary embolism: a multicenter prospective study. J Thromb Haemost. 2009;7:391-398.

96. Januzzi JL Jr, Camargo CA, Anwaruddin S, et al. The N-terminal Pro-BNP investigation of dyspnea in the emergency department (PRIDE) study. Am J Cardiol. 2005;95:948-954.

97. Donzé J, Le Gal G, Fine M, et al. Prospective validation of the Pulmonary Embolism Severity Index. A clinical prognostic model for pulmonary embolism. Thromb Haemost. 2008;100:943-948.

98. Safety Study of Outpatient Treatment for Pulmonary Embolism (OTPE). NCT00425542. January 15, 2009. Accessed on March 1, 2009. Available from http://www.clinicaltrial.gov/.

99. PEITHO Pulmonary Embolism Thrombolysis Trial. NCT00639743. May 26, 2008. Accessed on March 1, 2009. Available from http://www. clinicaltrial.gov/.
Vascular Health and Risk Management

\section{Publish your work in this journal}

Vascular Health and Risk Management is an international, peerreviewed journal of therapeutics and risk management, focusing on concise rapid reporting of clinical studies on the processes involved in the maintenance of vascular health; the monitoring, prevention and treatment of vascular disease and its sequelae; and the involvement of

\section{Dovepress}

metabolic disorders, particularly diabetes. This journal is indexed on PubMed Central and MedLine. The manuscript management system is completely online and includes a very quick and fair peer-review system, which is all easy to use. Visit http://www.dovepress.com/ testimonials.php to read real quotes from published authors. 